\title{
Exposure to Penile Cancer: The View of Patients with Human Papillomavirus
}

\author{
Maria Lúcia Neto de Menezes ${ }^{{ }^{*}}$, Maria das Neves Figueiroa ${ }^{1}$, \\ Estela Maria Leite Meirelles Monteiro², Evelliny da Silva Metódio ${ }^{3}$, Renato Daniel Melo da Silva ${ }^{4}$
}

${ }^{1}$ University of Pernambuco (UPE), Recife, Brazil

${ }^{2}$ Federal University of Pernambuco (UFPE), Recife, Brazil

${ }^{3}$ Regional Hospital “Dom Moura”, Garanhuns, Brazil

${ }^{4}$ Residency Program in Obstetric Nursing of Recife City, Recife, Brazil

Email: *maria.luciamenezes@yahoo.com.br

How to cite this paper: de Menezes, M.L.N., das Neves Figueiroa, M., Monteiro, E.M.L.M., da Silva Metódio, E. and da Silva, R.D.M. (2017) Exposure to Penile Cancer: The View of Patients with Human Papillomavirus. Open Access Library Journal, 4: e3600.

https://doi.org/10.4236/oalib.1103600

Received: April 13, 2017

Accepted: June 3, 2017

Published: June 6, 2017

Copyright (C) 2017 by authors and Open Access Library Inc.

This work is licensed under the Creative

Commons Attribution International

License (CC BY 4.0).

http://creativecommons.org/licenses/by/4.0/

\section{(c) (i) Open Access}

\begin{abstract}
This is a cross-sectional epidemiological study that analyzes knowledge about penile cancer among patients with human papillomavirus (HPV), monitored at the Reference Center for Urological Treatment of Arcoverde, Pernambuco, Brazil. The population of this study consisted of 27 men with a medical diagnosis of genital HPV infection within the period between 2008 and 2013. Age ranged between 20 and 49 years-old and most men were brown-skinned, married, and had a low socioeconomic status; also, most individuals were infected for more than 1 year and there was recurrence of HPV infection. We identified that $77.8 \%$ of the patients were unaware of the relationship between HPV and penile cancer. In addition to HPV infection, smoking and unprotected sex stood out as risk factors for penile cancer. The prevalence of penile cancer in the sample was $4 \%$. We concluded that HPV patients knew about penile cancer, but they did not associate this disease with the need to adopt mutilating treatments.
\end{abstract}

\section{Subject Areas \\ Public Health}

\section{Keywords}

Penile Neoplasms, Men's Health, Human Papillomavirus

\section{Introduction}

Cancer, as well as other chronic noncommunicable diseases, has become increasingly common worldwide and it can cause devastating damage. In developed 
and developing countries, cancer is a major public health problem, accounting for more than 6 million deaths each year, which represents $12 \%$ of all causes of death in the world. According to the World Health Organization (WHO), the worldwide distribution of cancer deaths is not homogenous. Data show a $15 \%$ to $25 \%$ increase in the mortality rate of developed countries. In turn, in developing countries, lower but increasing rates are observed, with an expectation of increasing from 5.4 million, in 2000, to 9.3 million, in 2020, according to population projections [1] [2] [3].

The incidence of this pathology is directly related to the region surveyed, i.e. developed countries have a lower incidence rate, in contrast to the high incidence in developing countries. Brazil is the country with the highest incidence of penile cancer in the world and the frequency of this neoplasm varies according to the region addressed. The Brazilian National Cancer Institute (INCA) estimated more than 4600 cases of penile cancer in the country in 2009, and the Northeast was the most prevalent region. In Brazil, penile cancer represents 2\% of all the cases of cancer in the male population, and it is more frequent in the North and Northeast regions than in the South and Southeast regions. It is noteworthy that, in these regions of higher incidence, penile cancer even outnumbers the cases of prostate and bladder cancer [4] [5] [6] [7].

Studies suggest an association between penile cancer with phimosis and human papillomavirus (HPV), and these are regarded as the most significant risk factors for penile cancer. According to Reis et al. [8], the presence of HPV in penile carcinomas was first demonstrated, in Brazil, in the 1980s. Molecular studies show that more than $50 \%$ of the penile carcinomas had HPV DNA detected, with prevalence of the oncogenic viral types 16 and 18 .

Actions to promote health and prevent health problems, associated with tertiary care focused on curative action, are a priority in order to reduce the rates of chronic diseases, especially when talking about cancer, which has shown an increase in its indicators. Such an increase reflects the increasing prevalence of exposure to risk factors, due to the intense urbanization process of the Brazilian population. This urbanization is characterized by increased consumption of industrialized foods and decreased physical activity and change of lifestyle [9].

Considering that absence or deficiency of information obstructs and/or hinders decision-making and behaviors that consolidate men's health promotion actions, we chose to conduct an analysis of knowledge about penile cancer among patients with HPV monitored at the Reference Center for Urological Treatment of Arcoverde.

\section{Material and Methods}

This research was carried out in the municipality of Arcoverde, "Sertão do Moxotó", Pernambuco, Brazil, $240 \mathrm{~km}$ far from the state capital, Recife, in the Regional Ambulatory of Medical Specialties "Dr. Paulo Siqueira", known as PAM; this institution has a mixed management, with collaboration between the State of Pernambuco and the Municipality of Arcoverde, and it operates at the building 
of the Brazilian National Institute of Social Security (INSS), as an annex of the Arcoverde Regional Hospital.

The population of this study consisted of men who were monitored in the PAM, by urologists and/or dermatologists, with a medical diagnosis of genital HPV infection. For the purpose of estimating the sample, we used the monthly average of medical consultations for men in the specialties of dermatology and urology, over 6 years (2008 to 2013), corresponding to 288 users, and the sampling calculation corresponded to 55 subjects.

Our sampling was probabilistic. The inclusion criteria were: man, regardless of the age group; medical diagnosis of genital HPV; inhabitant of Arcoverde; agreement to participate in the research, by signing the free and informed consent term. The exclusion criteria were: patients with any physical or psychic condition that made their effective participation in the research impossible (understand and answer the questions); and subjects who were not present in the municipality during the data collection period.

Data collection was conducted in September 2013, by referring to the medical records of the PAM and resorting to interviews at the households of patients who agreed to participate in the study. We used an interview form prepared by the authors, consisting of 25 objective and subjective questions, with variables related to data on sociodemographic profile, sexual behavior, medical diagnosis and treatment of HPV infection, knowledge about penile cancer, and risk factors. The data obtained have been analyzed through their absolute and percentage distributions, using descriptive statistics techniques.

The ethical issues were addressed according to Resolution 466/2012 of the Brazilian National Health Council (CNS). The study was approved by the Research Ethics Committee of the University of Pernambuco (UPE), under the Brazilian Certificate of Submission for Ethical Assessment (CAAE) 17823613.3.0000.5207 and the Expert Opinion 351,048.

\section{Results}

At the Urological Outpatient Clinic of the PAM, 27 cases of patients with HPV lesions were analyzed, treated between 2008 and 2013. The survey of patients' profile (Table 1) allowed us to find that the patients were aged from 20 to 49 years $(100 \%)$, who claimed to be brown-skinned (66.7\%), they had a family income from 1 to 5 minimum wages $(100 \%)$, they were single $(44.4 \%)$ or married/lived in a marriage-like relationship (44.4\%), sexually active $(88.9 \%)$, heterosexual (100\%), they did not use condoms regularly (55.5\%) and they had 2 or more sexual partners (33.3\%).

The prevalence of HPV infection was $9 \%$ among users of the urology outpatient clinic (Figure 1).

The analysis of patients' profile (Table 2) allowed us to identify that most individuals had a history of sexually transmitted disease (STD) (44.5\%), they were infected with HPV for more than 1 year (55.6\%), and they had a history of recurrence of HPV (55.6\%). Considering the analysis of the treatment adopted, the 


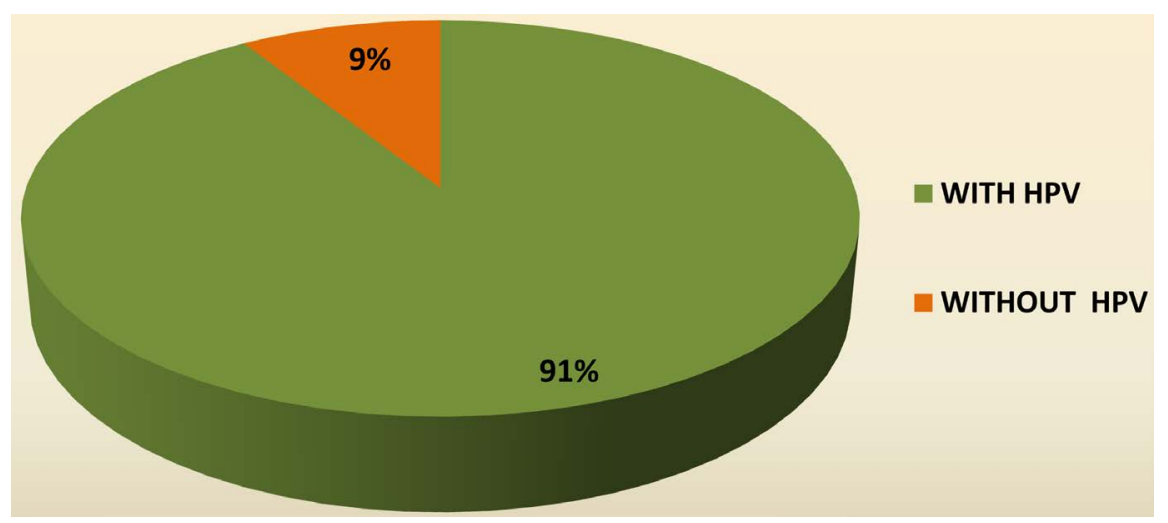

Figure 1. Prevalence of HPV lesions among users of the urology outpatient clinic. Arcoverde, 2013. Source: Prepared by the authors.

Table 1. Sociodemographic characteristics and data regarding the sexual behavior of patients with HPV monitored in a urology outpatient clinic. Arcoverde, 2013.

\begin{tabular}{|c|c|c|}
\hline Variables & $\mathbf{N}$ & $\%$ \\
\hline \multicolumn{3}{|l|}{ Age } \\
\hline 20 to 49 years & 27 & 100 \\
\hline \multicolumn{3}{|l|}{ Skin Colors } \\
\hline Brown & 18 & 66.7 \\
\hline White & 09 & 33.3 \\
\hline \multicolumn{3}{|l|}{ Family Income } \\
\hline 01 to 05 minimum wages & 27 & 100 \\
\hline \multicolumn{3}{|l|}{ Marital Status } \\
\hline Single & 12 & 44.4 \\
\hline Marriage/marriage like relationship & 12 & 44.4 \\
\hline Separated/Divorced & 03 & 11.2 \\
\hline \multicolumn{3}{|l|}{ Active sexual life } \\
\hline Yes & 24 & 88.9 \\
\hline No & 03 & 11.1 \\
\hline \multicolumn{3}{|l|}{ Sexual reference } \\
\hline Heterosexual & 27 & 100 \\
\hline \multicolumn{3}{|l|}{ Condom use } \\
\hline Yes & 12 & 44.5 \\
\hline Sometimes & 09 & 33.3 \\
\hline No & 06 & 22.2 \\
\hline \multicolumn{3}{|l|}{ Number of partners-last 3 months } \\
\hline 1 & 18 & 66.7 \\
\hline 2 or 3 & 06 & 22.2 \\
\hline 4 or more & 03 & 11.1 \\
\hline
\end{tabular}

Source: Prepared by the authors. 
Table 2. Characteristics of the urology outpatient users, related to the occurrence of HPV infection and the treatment adopted. Arcoverde, 2013.

\begin{tabular}{|c|c|c|}
\hline Variables & $\mathbf{N}$ & $\%$ \\
\hline \multicolumn{3}{|l|}{ History of STD } \\
\hline Yes & 12 & 44.5 \\
\hline No & 12 & 44.5 \\
\hline Do not how to inform & 03 & 11 \\
\hline \multicolumn{3}{|l|}{ Time of exposure to HPV } \\
\hline More than 1 year & 15 & 55.6 \\
\hline Less than 1 year & 06 & 22.2 \\
\hline Do not know & 06 & 22.2 \\
\hline \multicolumn{3}{|l|}{ HPV-recurrent infection } \\
\hline Yes & 15 & 55.6 \\
\hline No & 12 & 44.4 \\
\hline \multicolumn{3}{|l|}{ Type of treatment adopted } \\
\hline Application of trichloracetic acid-ATA & 09 & 33.3 \\
\hline Others: podophyllin/acetylsalicylic acid and lactic acid & 12 & 44.5 \\
\hline Do not know or did not mention & 06 & 22.2 \\
\hline \multicolumn{3}{|l|}{ Difficulty in performing treatment } \\
\hline Yes & 18 & 66.7 \\
\hline No & 09 & 33.3 \\
\hline \multicolumn{3}{|l|}{ Treatment outside the municipality } \\
\hline Yes & 24 & 88.8 \\
\hline No & 03 & 11.2 \\
\hline \multicolumn{3}{|l|}{ Partner investigated for HPV } \\
\hline Yes & 18 & 66.7 \\
\hline No & 09 & 33.3 \\
\hline
\end{tabular}

Source: Prepared by the authors.

application of trichloracetic acid (TAA) was cited by $33.3 \%$, followed by the use of podophyllin/acetylsalicylic acid and lactic acid (44.5\%). The difficulty to perform the treatment occurred in $66.7 \%$ of the responses, with treatment in the municipality in $88.8 \%$ of the cases and with a partner investigated in $66.7 \%$ of the cases.

Most respondents (88.8\%) have already heard about penile cancer, but they did not know the type of treatment adopted (88.8\%). They were also unaware of the relationship between HPV and penile cancer (77.8\%) and 44.4\% did not believe to be exposed to penile cancer due to HPV infection (Table 3).

Figure 2 highlights that smoking was the risk factor for penile cancer (except HPV) with the highest exposure among respondents (66.7\%), followed by unprotected sex (55.5\%). Phimosis and poor hygiene were also among the risk factors, however, with a lower prevalence. The prevalence of penile cancer among patients with HPV (sample studied for 6 years) was $4 \%$ (Figure 3). 


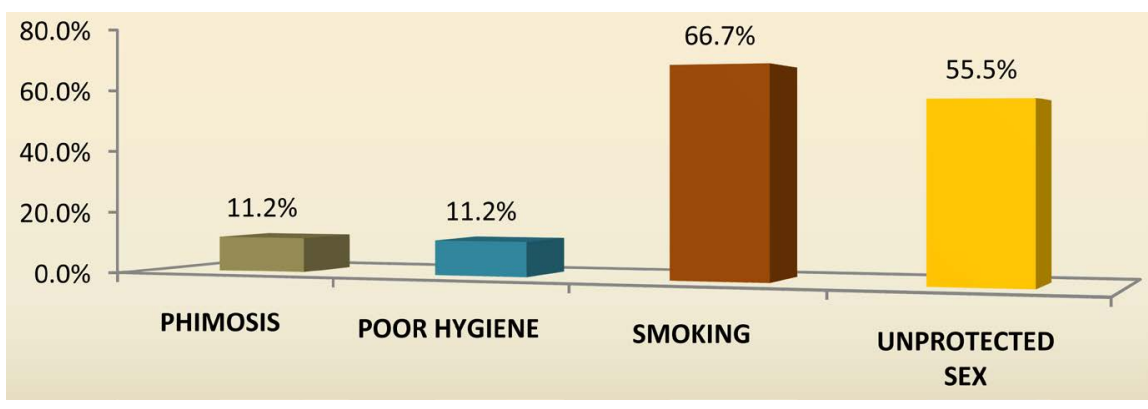

Figure 2. Prevalence of other risk factors for penile cancer among HPV patients monitored at the urology outpatient clinic. Arcoverde, 2013. Source: Prepared by the authors.

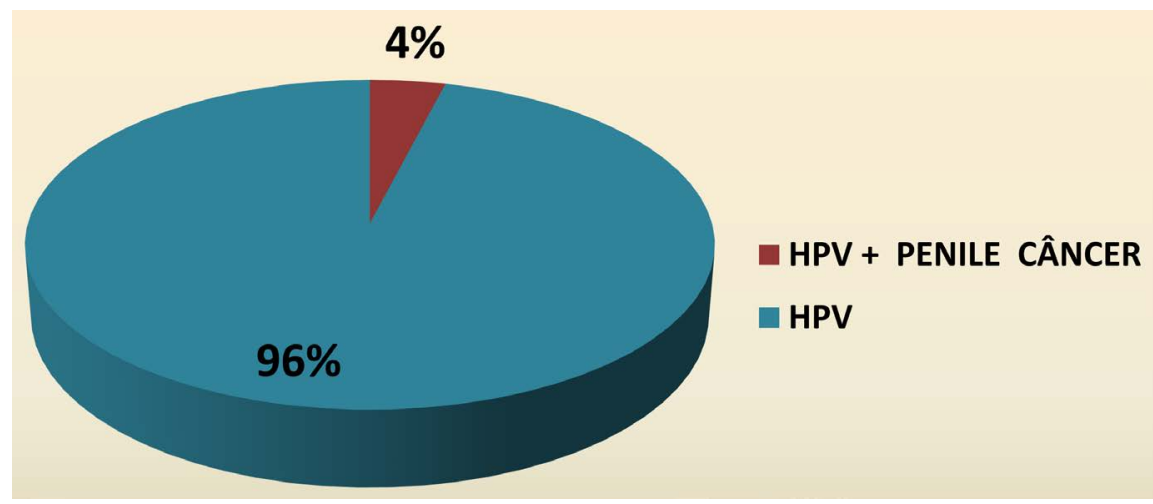

Figure 3. Prevalence of penile cancer among patients with HPV lesions monitored at the urology outpatient clinics. Arcoverde, 2013. Source: Prepared by the authors.

Table 3. Knowledge about penile cancer among HPV patients at the urology. Arcoverde, 2013.

\begin{tabular}{ccc}
\hline Variables & N & $\%$ \\
\hline Have already heard about penile cancer & & \\
Yes & 24 & 88.8 \\
No & 03 & 11.2 \\
No you know the type of treatment for penile cancer & & \\
No & 24 & 88.8 \\
Yes & 03 & 11.2 \\
Know whether there is a relationship between HPV and penile cancer & & \\
No & 21 & 77.8 \\
Yes & 06 & 22.2 \\
Believes to be exposed to penile cancer & & \\
Yes & 15 & 55.6 \\
No & 12 & 44.4 \\
\hline
\end{tabular}

Source: Prepared by the authors.

\section{Discussion}

Sample analysis revealed the existence of HPV infected men with a mean age < 60 years, something which corroborates the literature data, where there is a 
record of the incidence of this infection among men aged from 18 to 28 years. i.e. among young men, sexually active and engaged in risky sexual behavior, especially multiple partners, and those exposed to other STDs [8] [10] [11] [12].

The prevalence of HPV among healthy men ranges from 8 to 30\% [13], a number similar to that found in this study. However, this figure may be, according to the literature, even bigger and growing, when considering the potential of viral transmission and the global change in human behavior, favoring sexual exposure.

The findings of this study have evidenced men with HPV for more than 1 year and recurrent in most cases. This may be associated with the fact that HPV infection is usually asymptomatic or not apparent and even with lesion advancement, at first, it is painless. This factor causes men not to seek health care immediately, but only when they have been infected for some time, making it difficult to control the disease [14]. Moreover, culturally, men are less concerned with health and neglect self-care, they hardly notice themselves as patients and often deny the possibility of disease, seeking health care as the last resort, since by taking their illness, they would take a passive, dependent, and fragile role. In HPV infection, this relationship is no different [14] [15]. The treatment adopted in most cases was TAA and podophyllin, described in the literature as standard and safer treatment medicines [16].

Peniscopyis the examination of external genitalia (penis), by means of a colonoscope and solutions such as $5 \%$ acetic acid [17], and it allows us to visualizeclassic verrucous acuminate lesions, including minimal lesions; papular lesions that may exhibit, in addition to the papular aspect, visible vascular dots at varying degrees, or simply an acetopositive reaction; acetopositive flat lesions [11]. Some authors also report that peniscopyevidences many nonspecific findings, therefore, this method cannot confirm who is actually infected [18]. This information may justify the reduced number of records of that exam in our sample.

Patients' report on the difficulty to pursue treatment was noteworthy. This is due to the fact that many health facilities have low problem solving capability and they work with scheduling of appointments, allocating little or no space to meet spontaneous needs, besides not recognizing symptomatic STDs as emergency cases. This finding restricts accessibility to services, leading men with STDs to seek other means to solve their problem [19].

Due to their magnitude, transcendence, vulnerability to actions and feasibility of control, STDs should be prioritized. Care for STDs should be integrated by the Family Health Strategy (FHS), by the Brazilian primary health facilities (UBS), and by regionalized referral services. The recommendation of the Ministry of Health [19] is that primary health care (PHC), through the informational/educational actions taken in the community and the UBS, promotes greater population awareness regarding STDs. Consequently, there will be an earlier search for health services by individuals with suspected STDs and their partners, turning the UBS into gateways for these patients, thus reducing self-medication and the search for drug stores to tackle health-related problems [19]. 
Among the infected individuals, $1 / 3$ did not have an analysis of their sexual partners, a fact that reveals poor quality of health care, because this makes it impossible to interrupt the STD transmission chain, considering that early detection of cases is vital for health promotion. Moreover, advising patients with STDs is key for individuals to adopt health-prevention behaviors aimed at themselves and their sexual partners, thus avoiding the occurrence of new cases [19].

The prevalence of penile cancer was $4 \%$ in our sample, a rate much higher than that observed in the literature, which points out $2 \%$ in Brazil, within the general population [20]. Such a percentage is due to the fact that the study was conducted with individuals with HPV, something which is among the main risk factors for this type of cancer. According to Reis et al. [21], the prevalence of penile cancer among HPV-infected patients is about $40 \%$. Other studies have found that the presence of HPV in penile carcinoma ranges from 30 to $100 \%$ of the cases [22] [23] [24].

The HPV virus is capable of changing the cell cycle by expressing the E6 and E7 viral proteins in the inactivation and elimination of tumor suppressor gene products ( $\mathrm{p} 53$ and $\mathrm{Rb}$ ), consequently, it can contribute to the neoplastic process progression. The analysis of exposure to other risk factors for penile cancer in our sample, in addition to HPV, allowed us to highlight poor hygiene, phimosis, smoking, and unprotected sex. These risk factors are also stressed by other studies on the theme [4] [5] [8].

Among the other risk factors, smoking stood out, and it is worth mentioning because research shows that smokers are about 3 to 4.5 times more likely to develop penile carcinoma. Tobacco is referred to as a chemical carcinogen for multiple cancers, including penile cancer, due to combustion and metabolism of its components. Men with HPV who smoke are at even greater risk, because both (tobacco and HPV) have the ability to damage cellular DNA. Men who smoke more than 10 cigarettes a day have a 1.14-fold increased risk when compared to those who do not smoke. In some cultures, just as it occurs in rural Brazilian municipalities, there is a habit of chewing tobacco, a factor that increases the risk of penile cancer to 2.11 times [25] [26] [27].

Addressing knowledge about penile cancer, this research revealed that most respondents had lack of information on the theme, being unaware of the treatment and the association with STDs. This finding draws attention because it reveals the lack of health education activities aimed at the male population. It is noteworthy that health education should be regarded not only as an extra activity, but as an action that re-signifies the whole set of practices adopted by professionals at the UBS [20]. The Ministry of Health, through the Brazilian National Policy for Comprehensive Men's Health [7], recognizes that it is key to provide a basis for actions aimed at stimulating self-care and promoting inter-institutional coordination, especially with the education field, as a promoter of new ways of thinking and acting, in order to avoid health problems such as penile cancer, among others, considering that this is a disease with mutilating treatment and capable of leading to death. 


\section{Final Remarks}

This study revealed that patients with HPV, young men, sexually active and exposed to a STD for more than a year, faced difficulties to access treatment in the municipality. The main treatment adopted by the PHC was using TAA and podophyllin, with lack of records about the sexual partners of infected patients.

The prevalence of penile cancer was considered as high when compared to the general population and low when specifically related to patients with HPV. The subjects knew about penile cancer, but did not associate this disease with the need to adopt mutilating treatments, such as penectomy. Among the risk factors, in addition to HPV, attention was drawn to smoking, something which reinforces the need for educational measures aimed at quitting smoking.

In Brazil, the current health care model is still focused on individual curative care, based on hospital care. The empowerment of PHC, which is grounded in prevention and health education actions, associated with the empowerment of tertiary care, which is grounded in curative actions, stands out as a priority process to reduce the rates of chronic diseases in the country, mainly in relation to the types of cancer-whose indicators have increased in recent years.

This study observes the epidemiological method, which can raise the sociodemographic profile and survey respondents' opinions about penile cancer. Choosing the quantitative methodology allowed us to apply a structured interview instrument for collecting variables and presenting figures, in order to minimize subjective interference of the authors in information collection and presentation of results. However, the ability to process and analyze data provided by epidemiology does not allow us to bring concepts of the human and social sciences together. Thus, the main limitation of this study, which constitutes a proposal for further research, is bridging numerical data and its sociocultural interpretations with regard to men's opinion about cancer and its risks, as well as concerning poor self-care.

\section{References}

[1] Brasil (2012) ABC of Cancer: Primary Approaches to Cancer Control. 2nd Edition, INCA, Rio de Janeiro, RJ.

[2] Garófolo, A., Avesani, C.M., Camargo, K.G., Barros, M.E., Silva, S.R.J., Taddei, J.A.A.C., et al. (2004) Diet and Cancer: An Epidemiological View. Journal of Nutrition, 17, 491-505.

[3] Guerra, M.R., Gallo, C.V.M. and Mendonça, G.A.S.M. (2005) The Risk of Cancer in Brazil: Tendencies and Recent Epidemiologic Studies. Brazilian Journal of Cancero$\log$, 51, 227-234.

[4] Carvalho, N.S., Kannenberg, A.P., Munaretto, C., Yoshioka, D., Absy, M.C.V., Ferreira, M.A., et al. (2007) Association between HPV and Penile Cancer: Literature Review. STD: Brazilian Journal of Sexually Transmitted Diseases, 19, 92-95.

[5] Paula, A.A.P., Netto, J.C.A., Cruz, A.D. and Freitas Júnior, R. (2005) Penile Squamous Carcinoma: Epidemiological, Histopathological, Viral Influence and Surgical Considerations. Brazilian Journal of Cancerology, 51, 243-252.

[6] Souza, D.R. and Catão, R.M.C. (2012) The Importance of Knowledge about Human 
Papillomavirus: General Considerations. Journal of Biology and Pharmacy, 8, 19834209.

[7] Brasil (2008) Brazilian National Policy of Men's Comprehensive Care: Principles and Guidelines. Ministério da Saúde, Brasília, DF.

[8] Reis, A.A.S., Paula, L.B., Paula, A.A.P., Saddi, V.A. and Cruz, A.D. (2010) ClinicoEpidemiological Aspects Associated with Penile Cancer. Science \& Collective Health, 15, 1105-1111.

[9] Cestari, M.E.W. and Zago, M.M.F. (2005) Cancer Prevention and Health Promotion: A Challenge for the 21st Century. Brazilian Journal of Nursing, 58, 218221.

[10] Buosil, L. and Oliveira, L.F.C. (2007) Approach to the Partner of a Women Diagnosed with HPV. Secretaria de Estado de Saúde do Distrito Federal, Brasília, DF.

[11] Chaves, J.H.B., Vieira, T.K.B., Ramos, J.S. and Bezerra, A.F.S. (2011) Peniscopy in Screening Lesions Induced by Human Papilloma Virus. Journal of the Brazilian Society of Medical Clinic, 9, 30-35.

[12] Reis, A. (2005) The Role of Human Papillomavirus in the Carcinogenesis of Penile Tumors: An Epidemiological and Molecular Approach. PUC Goiás, Goiânia, GO.

[13] Giuliano, A.R., Tortolero, L.G., Ferrer, E., Burchell, N.A., Sanjose, S., Kjaer, S.K., et al. (2008) Epidemiology of Human Papillomavirus Infection in Men, Cancers Other than Cervical and Benign Conditions. Vaccine, 26, K17-K28.

https://doi.org/10.1016/j.vaccine.2008.06.021

[14] Arcoverde, M.A.M. and Wall, M.L. (2005) Assistance Given to the Carried Masculine Being of the HPV: Contributions of Nursing. STD: Brazilian Journal of Sexually Transmitted Diseases, 17, 133-137.

[15] Gomes, R., Nascimento, E.F., Rebello, L.E.F.S. and Araújo, F.C. (2008) The Touched Masculinity: A Discussion about the Digital Rectal Exam for Prostate Cancer Prevention. Science \& Collective Health, 13, 1975-1984.

[16] Carvalho, J.J.M. (2004) HPV Practical Handbook: Human Papillomavirus. Instituto Garnet, São Paulo, SP.

[17] Roberto, J.C.S. (2005) Prevalence of Human Papillomavirus (HPV) Infection in HIV-Serotype Men and Partners of Women with HPV Infection. Universidade de São Paulo, São Paulo, SP.

[18] Rosenblatt, C., Lucon, A.M., Pereyra, E.A.G., Pinnotti, J.A. and Arap, S. (2004) Human Papillomavirus in Men-“To Screen or not to Screen"-A Review. Einstein, 2, 212-216.

[19] Brasil (2006) Sexually Transmitted Disease Control Handbook. 4th Edition, Ministério da Saúde, Brasília, DF.

[20] Souza, K.W., Reis, P.E.D., Gomes, I.P. and Carvalho, E.C. (2011) Prevention Strategies for Testicular and Penile Cancer: An Integrative Review. Journal of the USP School of Nursing, 45, 277-282.

[21] Reis, A.M.B., Carneiro, M.A.S., Del-Rios, N.H.A., Souza, D.H.R.L., Peclat, A.A. and Matos, M.A.D. (2011) Prevalence of Human Papillomavirus (HPV) Infection in Sexually Active Men with Penile Cancer in the State of Goiás, Brazil. Universidade Federal de Goiás, Goiânia, GO.

[22] Bezerra, A.L., Lopes, A., Santiago, G.H., Ribeiro, K.C., Latorre, M.R. and Villa, L.L. (2001) Human Papillomavirus as a Prognostic Factor in Carcinoma of the Penis: Analysis of 82 Patients Treated with Amputation and Bilateral Lymphadenectomy. Cancer, 91, 2315-2321. 
https://doi.org/10.1002/1097-0142(20010615)91:12<2315::AID-CNCR1263>3.0.CO; $\underline{2-\mathrm{C}}$

[23] Neves, D., Camara, G.N.L., Alencar, T.R., Da Cruz, M.R., Martins, C.R.F. and Carvalho, L.G.S. (2002) Prevalence of Human Papillomavirus in Penile Carcinoma. Brazilian Journal of Urology, 28, 221-226.

[24] Tornesello, M.L., Duraturo, M.L., Losito, S., Botti, G., Pilotti, S., Stefanon B., et al. (2008) Human Papillomavirus Genotypes and HPV16 Variants in Penile Carcinoma. International Journal of Cancer, 122, 132-137. https://doi.org/10.1002/ijc.23062

[25] Passos, M.R.L., Almeida, G., Giraldo, P.C., Cavalcanti, S.M.B., CôrtesJunior, J.C., Bravo, R.S., et al. (2008) Human Papillomavirusis in Genital, PartI. STD: Brazilian Journal of Sexually Transmitted Diseases, 20, 108-124.

[26] Pow-Sang, M.R., Ferreira, U., Pow-Sang, J.M., Nardi, A.C. and Destefano, V. (2010) Epidemiology and Natural History of Penile Cancer. Urology, 76, S2-S6. https://doi.org/10.1016/j.urology.2010.03.003

[27] Instituto Oncoguia (2013) Prevention: Risk Factors for Penile Cancer. http://www.oncoguia.org.br/conteudo/cancer-de-penis/2435/31/

Submit or recommend next manuscript to OALib Journal and we will provide best service for you:

- Publication frequency: Monthly

- 9 subject areas of science, technology and medicine

- Fair and rigorous peer-review system

- Fast publication process

- Article promotion in various social networking sites (LinkedIn, Facebook, Twitter, etc.)

- Maximum dissemination of your research work

Submit Your Paper Online: Click Here to Submit

Or Contact service@oalib.com 